Heteroatom Chemistry

Volume 19, Number 2, 2008

\title{
Reactivity of Phosphiranes Toward Nucleophiles: Theoretical and Experimental Investigations
}

\author{
Michelle L. Coote, Elizabeth H. Krenske, Ilham Maulana, \\ Jörg Steinbach, and S. Bruce Wild
}

Research School of Chemistry, The Australian National University, Canberra ACT 0200, Australia

Received 3 April 2007; revised 8 July 2007

\begin{abstract}
The thermodynamic and kinetic parameters for the reaction of 1-methylphosphirane with dimethylphosphide $\left(\mathrm{PMe}_{2}^{-}\right)$, proceeding via attack at the ring phosphorus atom to give $M e_{2} P-P M e^{-}$plus ethylene, were calculated at the G3(MP2)-RAD(+) level. The rate constant for this mechanism $(k=1.1$ $\times 10^{13} \mathrm{~L} \mathrm{~mol}^{-1} \mathrm{~s}^{-1}$ at $25^{\circ} \mathrm{C}$ ) is seven orders of magnitude greater than that for the previously studied mechanism involving attack at carbon. Experimental investigations with 1-phenylphosphirane gave consistent results: Treatment with LiPMePh yielded no detectable polymer, and quenching with MeI gave the known diphosphine $\left(R^{*}, R^{*}\right)-( \pm) /\left(R^{*}, S^{*}\right)-M e P h P-$ $P M e P h$. (c) 2008 Wiley Periodicals, Inc. Heteroatom Chem 19:178-181, 2008; Published online in Wiley InterScience (www.interscience.wiley.com). DOI 10.1002/hc.20405
\end{abstract}

\section{INTRODUCTION}

Small-ring phosphorus heterocycles, such as phosphiranes (1), have recently attracted interest as precursors to polyphosphines. For example, the ringopening polymerization of $1\left(\mathrm{R}=2,4,6^{-t} \mathrm{Bu}_{3}-\mathrm{C}_{6} \mathrm{H}_{2}\right)$ under (cationic) initiation by MeI or MeOTf has been used to prepare a polymer with the backbone struc-

Correspondence to: Michelle L. Coote and S. Bruce Wild; e-mail: mcoote@rsc.anu.edu.au and sbw@rsc.anu.edu.au.

Contract grant sponsor: Australian Research Council Discovery Grant.

(c) 2008 Wiley Periodicals, Inc. ture $\left[\mathrm{P}(\mathrm{R}) \mathrm{CH}_{2} \mathrm{CH}_{2}\right]_{n}[1]$. We have previously reported computational studies of the radical polymerization of phosphiranes and found that the most likely pathway involved attack by a $C$-centered radical at a ring phosphorus atom [2]. In subsequent work, we studied the anionic ring opening of $\mathbf{1}(\mathrm{R}=\mathrm{Me})$, giving consideration to a mechanism involving attack by $\mathrm{PMe}_{2}^{-}$at carbon (Scheme 1, step 1), and found that it should be fast enough $\left(k=6.2 \times 10^{5} \mathrm{~L} \mathrm{~mol}^{-1} \mathrm{~s}^{-1}\right.$ at $25^{\circ} \mathrm{C}$ ) to enable a practical synthesis of polyphosphines 3 [3]. The borane adduct of $\mathbf{1}(\mathrm{R}=\mathrm{Me})$ had a similar rate constant $\left(k=6.8 \times 10^{4} \mathrm{~L} \mathrm{~mol}^{-1} \mathrm{~s}^{-1}\right)$.

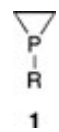

We wished to use these nucleophilic ringopening reactions to prepare polyphosphines of the type 3. However, previous experimental studies have shown that the phosphirane ring can react with a nucleophile at phosphorus because of the polarization $\mathrm{P}^{\delta+}-\mathrm{C}^{\delta-}$ of the $\mathrm{P}-\mathrm{C}$ ring bond [4]. Depending on the substituents, this can be accompanied by cleavage of one or both of the $\mathrm{P}-\mathrm{C}$ ring bonds. For example, it was found that treatment of the coordinated phosphirane in $\mathbf{4}$ with a hard nucleophile such as $\mathrm{RO}^{-}$or $\mathrm{R}_{2} \mathrm{~N}^{-}$led to cleavage of one $\mathrm{P}-\mathrm{C}$ bond, whereas soft nucleophiles such as $\mathrm{R}_{2} \mathrm{P}^{-}$and $\mathrm{RS}^{-}$led to cleavage of both [5]. In the latter case, styrene was liberated (Scheme 2). 


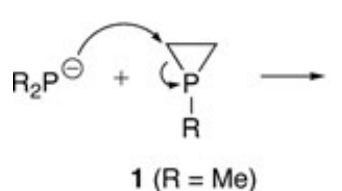<smiles>[R]CCP[O]</smiles>

2

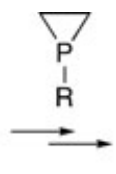<smiles>[R7]CCP([R])CCP</smiles>

3

SCHEME 1

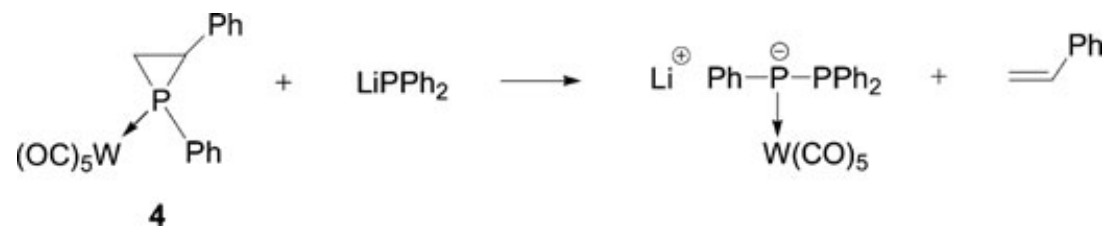

\section{SCHEME 2}

We, therefore, set out to determine whether a similar mode of reaction would be found for free phosphiranes. We have used ab initio molecular orbital calculations at the G3(MP2)-RAD(+) level [6] to investigate the dimethylphosphide-induced dissociation of 1-methylphosphirane into $\mathrm{Me}_{2} \mathrm{P}-\mathrm{PMe}^{-}$ (5) and ethylene, and then experimentally examined the reaction of 1-phenylphosphirane $(1, \mathrm{R}=\mathrm{Ph})$ with lithium methylphenylphosphide.

\section{RESULTS AND DISCUSSION}

Molecular geometries, obtained at the B3-LYP/6$31+\mathrm{G}(\mathrm{d})$ level, for the attack of the $\mathrm{PMe}_{2}^{-}$ ion at the ring-carbon and phosphorus in 1-methylphosphirane, are shown in Scheme 3. The calculated thermodynamic and kinetic parameters [7] for the two modes of attack are given in Table 1.

The calculated equilibrium constants indicate that attack at carbon and attack at phosphorus are both thermodynamically very favorable. This primarily reflects the release of ring strain. However, the rate constant for attack at phosphorus $(k=1.1$ $\left.\times 10^{13} \mathrm{~L} \mathrm{~mol}^{-1} \mathrm{~s}^{-1}\right)$ is approximately a factor of $10^{7}$ greater than for attack at carbon $\left(k=6.2 \times 10^{5}\right.$ $\mathrm{L} \mathrm{mol}^{-1} \mathrm{~s}^{-1}$ ). This is presumably due to the lesser Coulombic repulsion in the transition state when attack occurs at phosphorus.

During attack at phosphorus, the $\mathrm{PMe}_{2}^{-}$ion approaches roughly in the plane of the ring, leading to an unsymmetrical transition state in which the two breaking $\mathrm{P}-\mathrm{C}$ bonds differ in length by $0.331 \AA$ and

Attack at C:

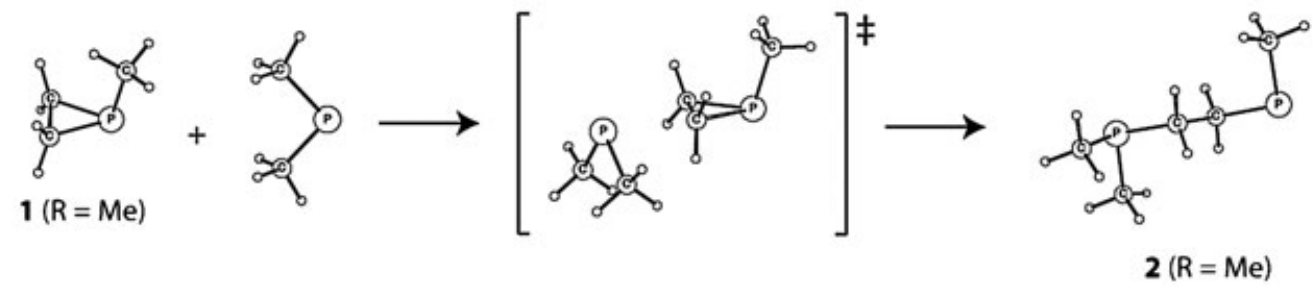

Attack at $P$ :

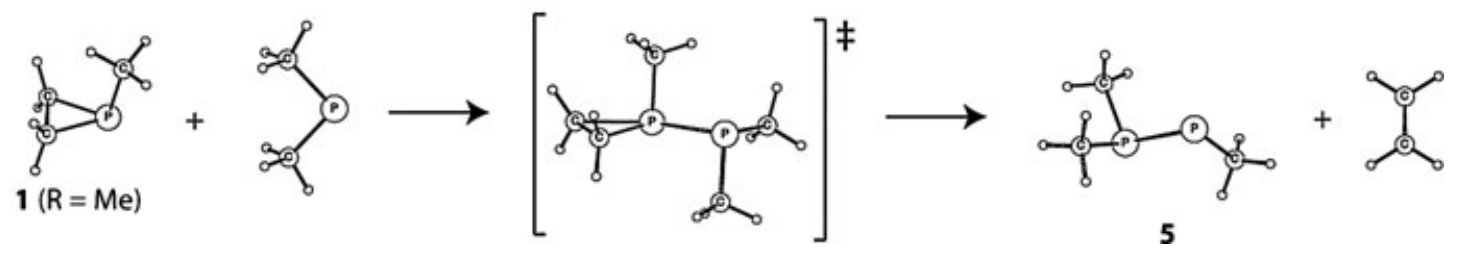


TABLE 1 Calculated Thermodynamics and Kinetics $\left(25^{\circ} \mathrm{C}\right)$ of the Ring Opening of $1(\mathrm{R}=\mathrm{Me})$ by $\mathrm{PMe}_{2}^{-}$

\begin{tabular}{lcc}
\hline & Attack at $C^{a}$ & Attack at $P$ \\
\hline$\Delta H\left(\mathrm{~kJ} \mathrm{~mol}^{-1}\right)$ & -123.5 & -91.0 \\
$\Delta S\left(\mathrm{~J} \mathrm{~K}^{-1} \mathrm{~mol}^{-1}\right)$ & -145.8 & 19.1 \\
$\Delta G\left(\mathrm{~kJ} \mathrm{~mol}^{-1}\right)$ & -80.1 & -96.7 \\
$K$ & $2.6 \times 10^{15}$ & $8.7 \times 10^{16}$ \\
$\Delta H^{\ddagger}\left(\mathrm{kJ} \mathrm{mol}^{-1}\right)$ & 8.6 & -39.3 \\
$\Delta S^{\ddagger}\left(\mathrm{J} \mathrm{K}^{-1} \mathrm{~mol}^{-1}\right)$ & -131.7 & -153.7 \\
$\Delta G^{\ddagger}\left(\mathrm{kJ} \mathrm{mol}^{-1}\right)$ & 47.9 & 6.6 \\
$k\left(\mathrm{~L} \mathrm{~mol}^{-1} \mathrm{~s}^{-1}\right)$ & $6.2 \times 10^{5}$ & $1.1 \times 10^{13}$
\end{tabular}

${ }^{a}$ From [3].

the more detached carbon atom bears an increased negative charge (natural charge -0.852 in the TS, compared with -0.645 in the reactant). It was, therefore, suspected that the carbanionic species 6 might be an intermediate en route to $\mathbf{5}$. However, species 6 was found to lie $14.6 \mathrm{~kJ} \mathrm{~mol}^{-1}$ above the transition structure (relative enthalpies at $25^{\circ} \mathrm{C}$ at the G3(MP2)$\mathrm{RAD}(+)$ level), which suggests that the cleavage of the two $\mathrm{P}-\mathrm{C}$ bonds is a concerted process.

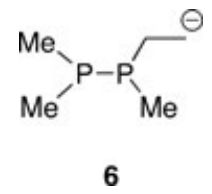

The large difference in rate constants for the two pathways suggests that, although the propagation step of the desired anionic polymerization of free phosphiranes is facile [3], the polymerization is likely to be hampered by attack at phosphorus. We have found this to be borne out by experiment. When the phosphirane $1(\mathrm{R}=\mathrm{Ph})$ [8] was treated with lithium methylphenylphosphide as initiator in THF, no evidence was found in the ${ }^{31} \mathrm{P}\left\{{ }^{1} \mathrm{H}\right\}$ NMR spectrum for the formation of poly(1-phenylphosphirane), although there were in the spectrum numerous peaks in the region -43 to $-5 \mathrm{ppm}$. However, when a solution of $1(\mathrm{R}=\mathrm{Ph})$ was treated with a stoichiometric amount of lithium methylphenylphosphide in THF, and the intermediate phosphinophosphide then treated with iodomethane (Scheme 4), the formation of the known diphosphine $\left(R^{*}, R^{*}\right)$ $( \pm) /\left(R^{*}, S^{*}\right)-7$ was evident from the presence of singlets at $\delta-39.8$ and -36.2 for the two diastereomers in the ${ }^{31} \mathrm{P}\left\{{ }^{1} \mathrm{H}\right\}$ NMR spectrum in $\mathrm{C}_{6} \mathrm{D}_{6}$ at $25^{\circ} \mathrm{C}$ [9-11].

The propensity for nucleophiles to attack the phosphirane ring at phosphorus rather than at carbon is predominantly a kinetic effect reflecting the polarity of the $\mathrm{P}-\mathrm{C}$ bond. Although this reduces the utility of anionic ring opening as a general route to poly(phosphiranes), it is possible that successful polymerization may be achieved if the polarity of the $\mathrm{P}-\mathrm{C}$ ring bonds were reversed through appropriate choice of substituents.

\section{EXPERIMENTAL}

All reactions were carried out under a nitrogen or argon atmosphere using Schlenk techniques. Solvents were purified by conventional methods and stored under nitrogen or argon [12]. ${ }^{1} \mathrm{H}$ and ${ }^{31} \mathrm{P}\left\{{ }^{1} \mathrm{H}\right\}$ NMR spectra were recorded on Varian VXR 300S and Gemini 300 spectrometers operating at 300.1 $\mathrm{MHz}\left({ }^{1} \mathrm{H}\right)$ and $121.5 \mathrm{MHz}\left({ }^{31} \mathrm{P}\right)$ with chemical shifts being expressed in ppm downfield from internal $\mathrm{Me}_{4} \mathrm{Si}\left({ }^{1} \mathrm{H}\right)$ and external $85 \%$ aqueous $\mathrm{H}_{3} \mathrm{PO}_{4}\left({ }^{31} \mathrm{P}\right)$. Methylphenylphosphine was distilled and kept under argon [13]. n-Butyllithium and iodomethane were used as supplied by Sigma-Aldrich.

1-Phenylphosphirane was synthesized according to the published method [8], and kept briefly in THF solution ( $1 \mathrm{~d}$ ) prior to use. For the dilithiation of phenylphosphine, however, a 2:1 mixture of $n$-hexane and THF was used as solvent instead of pure THF, so as to decrease the solubility of the product (THF is needed to stabilize the product in the form of a complex, otherwise the powder obtained is pyrophoric). The crude 1-phenylphosphirane was distilled directly from the reaction mixture without initial separation of the lithium chloride. This improved the yield from $21 \%$ to $29 \%$.

$\left(R^{*}, R^{*}\right)-( \pm) /\left(R^{*}, S^{*}\right)-1,2-$ Dimethyl-1,2diphenyldiphosphine $\left.\left(R^{*}, R^{*}\right)-( \pm)-/ R^{*}, S^{*}\right)-7$

In a tube equipped with a septum, a solution of methylphenylphosphine $(0.25 \mathrm{~mL}, 2.9 \mathrm{mmol})$ in

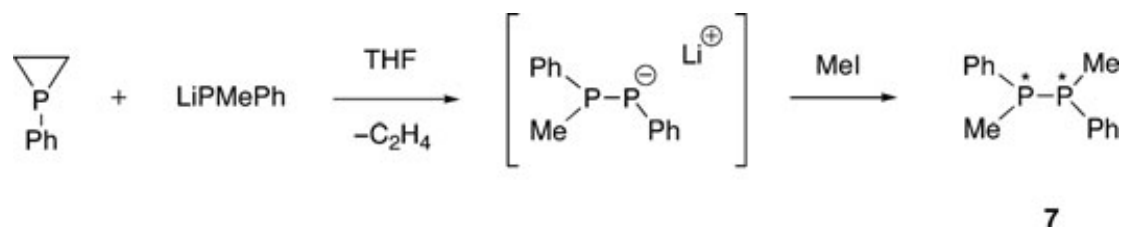

\section{SCHEME 4}


THF (6 mL) was cooled to $-78^{\circ} \mathrm{C}$ (acetone/dry ice). A solution of $n$ butyllithium (1.6 M in $n$-hexane, 1.8 $\mathrm{mL}, 2.9 \mathrm{mmol}$ ) was added via syringe, and the resulting orange solution was stirred for a further $10 \mathrm{~min}$ before 1-phenylphosphirane $(0.35 \mathrm{~mL}, 2.9 \mathrm{mmol})$ was added. The solution was then allowed to warm to room temperature, during which time the color changed to dark yellow. The mixture was quenched with iodomethane $(0.18 \mathrm{~mL}, 2.9 \mathrm{mmol})$, whereupon the color disappeared. After removal of the solvent and other volatile components in vacuo, a colorless oil was obtained, which was identified as the diphosphine $\left(R^{*}, R^{*}\right)-( \pm) /\left(R^{*}, S^{*}\right)$-MePhPPMePh (7) by comparison of its ${ }^{31} \mathrm{P}\left\{{ }^{1} \mathrm{H}\right\}$ NMR data, viz. $\delta_{\mathrm{P}}-39.8(\mathrm{~s})$, $-36.2(\mathrm{~s})\left(\mathrm{C}_{6} \mathrm{D}_{6}\right)$, with the literature values, viz. $\delta_{\mathrm{P}}$ $40.5(\mathrm{~s}), 36.9(\mathrm{~s})\left(\mathrm{C}_{6} \mathrm{H}_{6}\right)[11]$.

\section{SUPPLEMENTARY INFORMATION}

B3-LYP/6-31+G(d) geometries, in the form of Gaussian archive entries, are available from the author on request (mcoote@rsc.anu.edu.au).

\section{ACKNOWLEDGMENTS}

We gratefully acknowledge generous allocations of computing time from the Australian Partnership for Advanced Computing and the Australian National University Supercomputer Facility.

\section{REFERENCES}

[1] Kobayashi, S.; Kadokawa, J.-I. Macromol Rapid Commun 1994, 15, 567-571.

[2] Hodgson, J. L.; Coote, M. L. Macromolecules 2005, $38,8902-8910$.

[3] Coote, M. L.; Hodgson, J. L.; Krenske, E. H.; Wild, S. B. Heteroat Chem 2007, 18, 118-128.

[4] See, for example, Mathey, F. Chem Rev 1990, 90, 9971025.

[5] Marinetti, A.; Mathey, F. Tetrahedron 1989, 45, 30613070.

[6] The computational methods used were the same as those used in [3], wherein a full description is supplied. The G3(MP2)-RAD(+) method is a highlevel procedure that attempts to reproduce coupledcluster $[\operatorname{CCSD}(\mathrm{T})]$ energies with a large triple zeta basis set using additivity corrections carried out at the RMP2 level.

[7] Thermodynamic and kinetic parameters were calculated by the methods described in [3]. The variational transition state for attack at phosphorus was identified by a relaxed scan along the forming $(\mathrm{P}-\mathrm{P})$ bond length at the B3-LYP/6-31+G(d) level.

[8] Hockless, D. C. R.; Kang, Y. B.; McDonald, M. A.; Pabel, M.; Willis, A. C.; Wild, S. B. Organometallics 1996, 15, 1301-1306.

[9] Fluck, E.; Issleib, K. Chem Ber 1965, 98, 2674-2680.

[10] Lambert, J. B.; Jackson, G. F., III; Mueller, D. C. J Am Chem Soc 1968, 90, 6401-6405.

[11] McFarlane, H. C. E.; McFarlane, W. J Chem Soc, Chem Commun 1971, 1589-1590.

[12] Armarego, W. L. F.; Chai, C. L. L. Purification of Laboratory Chemicals, 5th ed.; Butterworth-Heinemann: Amsterdam, 2003; Ch. 4.

[13] Roberts, N. K.; Wild, S. B. J Am Chem Soc 1979, 101, 6254-6260. 